\title{
Dropping Shock Characteristics of the Suspension Cushioning System with Critical Components
}

\author{
Hui Li, ${ }^{1}$ Anjun Chen, ${ }^{1,2}$ and Ningning Duan ${ }^{1}$ \\ ${ }^{1}$ Department of Packaging Engineering, Jiangnan University, Wuxi, Jiangsu 214122, China \\ ${ }^{2}$ Jiangsu Province Key Laboratory of Advanced Food Manufacturing Equipment and Technology, Wuxi, Jiangsu 214122, China \\ Correspondence should be addressed to Anjun Chen; caj62@jiangnan.edu.cn
}

Received 22 July 2017; Accepted 29 August 2017; Published 13 November 2017

Academic Editor: Hugo Rodrigues

Copyright (c) 2017 Hui Li et al. This is an open access article distributed under the Creative Commons Attribution License, which permits unrestricted use, distribution, and reproduction in any medium, provided the original work is properly cited.

\begin{abstract}
Dimensionless dropping shock dynamic equations of suspension nonlinear packaging system with critical components were obtained. The numerical results of shock response were gained using Runge-Kutta method. To evaluate the dropping shock characteristics of critical components, the dropping damage boundary curve was established, where the system parameter and the dimensionless shock velocity were selected as two coordinate parameters. Then, the frequency ratio and the system damping ratio were taken as third basic parameters of the dropping damage boundary surface, respectively. To study dynamic properties of the suspension system with critical components, the shock response acceleration, shock response displacements, and dropping damage boundary were analyzed. Based on the numerical results, the effects of the relevant parameters on dropping shock response and damage boundary of critical component were investigated. It is demonstrated that both a higher frequency ratio and a system damping ratio in the specific range can exert a positive effect on the product protection and should be selected in design process of the suspension system. Furthermore, with the decrease of suspension angle, the acceleration response peak decreases, the displacement response peak increases, and the safety zone enlarges.
\end{abstract}

\section{Introduction}

The concept of the product fragility is the foundation for dynamics of packaging cushioning [1]. But the value of the fragility cannot be obtained exactly and a valid damage evaluation method needs to be found. According to extensive investigation, both shock and vibration are main dynamic factors of damage for the product in the transportation. For evaluating the damage potential of impacts to a product, the two-dimensional damage boundary concept was suggested [2]. However, this concept was assumed that the cushion pad was not only linear elastic material but also thick enough; furthermore, only when the maximum acceleration response value exceeded the product fragility can the product be damaged. Thus, this theory may be limited in the practical application. Then, some researchers presented the subsequent improved damage evaluation methods, that is, fatigue damage boundary concept $[3,4]$ and displacement damage boundary concept [5]. Because dropping shock is one of the main factors that cause the mechanical damage of most packaged products potentially in the transportation, the numerical results of a nonlinear cushioning system were derived by applying Runge-Kutta method and the dropping damage boundary concept of the packaged article was proposed [6], but no research has been conducted on whether the drop equivalent test is still suitable for nonlinear system. Then, some researchers improved the accuracy of a nonlinear system drop test $[7,8]$. For taking into consideration the damage of cumulative fatigue, the repetitive-shock-induced damage of the product was analyzed by conducting drop tests [9].

For the Runge-Kutta method that is used to solve nonlinear system problem, one advantage of this Runge-Kutta method is high calculation accuracy, but this numerical approach cannot present this relationship of relevant parameters clearly. To make the relationship clear in the relevant expressions of nonlinear dynamic models, variational iteration method (VIM) was used to obtain the dropping shock properties of nonlinear packaging systems [10-12]. 
Note that the research objects that were mentioned above were treated as a single degree of freedom system. In fact, the products include many critical parts and should be regarded as multidegree of freedom system and nonlinear system by nature. Therefore, some researchers investigated the dropping damage evaluation of the typical material nonlinear packaging system with two degrees of freedom [13-16], which enriches the dropping damage boundary theory of products. Note that the aforesaid material nonlinear packaging system is just one of the cushioning packaging systems, and geometric nonlinear systems are also indispensable in product protection. Furthermore, the geometric nonlinear systems show excellent cushioning properties and should be further researched. Thus, some authors researched the shock characteristics of titled support spring geometric nonlinear system with critical components $[17,18]$.

The suspension system usually shows distinguished properties against shock and vibration and was devoted to protecting electronic product by some authors [19]. However, the fragile components were connected to the base through a spring. To further study the suspension system, the model of suspension system with eight springs as cushioning components was established, and the dynamic properties of the suspension system have been given insights into by some researchers, such as nature vibration [20], the shock response, and damage evaluation properties under classical pulse excitation [21, 22]. To show the relationship of correlation parameters of the suspension system clearly, several authors obtained the first-order approximate solution of system by applying the VIM and analyzed the effects of the relevant system parameters on the dropping damage boundary of suspension system $[23,24]$. However, those aforementioned studies mainly focus on one-degree-of-freedom suspension system, and it has no research on the dynamic characteristics of two-degree-of-freedom suspension systems with critical components, especially on the dropping shock characteristics of the system.

In this paper, the dimensionless nonlinear dynamic equations of two-degree-of-freedom suspension system with critical components were established. The numerical results of this dimensionless dynamic equations were derived by applying the fourth-order Runge-Kutta method. To evaluate the dropping shock response and potential damage of critical components, the effects of the suspension angle, the frequency ratio, and the damping ratios on shock response and dropping damage boundary of critical components were discussed.

\section{Modeling and Dimensionless Equations}

The two-degree-of-freedom model of the suspension system is derived in Figure 1(a). The main body of the product is suspended in the center of container ADGH-A $\mathrm{D}^{\prime} \mathrm{G}^{\prime} \mathrm{H}^{\prime}$ by eight springs, that is, four springs on the top and the rest on the bottom. $m_{1}$ and $m_{2}$ denote the mass of critical components and main body; $k_{1}$ and $k$ denote stiffness coefficient of the junction linking critical components to main part and the suspension system; $c_{1}$ and $c_{2}$ are the damping coefficient of the junction linking critical components to main part and the suspension system; $\phi_{0}$ is the suspension angle; $l_{0}$ is the original length of suspension spring, respectively.

To evaluate the dropping shock dynamic characteristics of critical components, it is assumed that the system falls from the height $H$. The static equilibrium positions of main part and critical components are selected as the origins, and the downward direction is defined as plus direction. The stress analysis diagram of critical components and the main part can be derived from Figure 1(b), where $F$ is the force of suspension springs acting on main body in vertical direction. The motion of critical components can be obtained as

$$
m_{1} \ddot{x}_{1}+k_{1}\left(x_{1}-x_{2}\right)+c_{1}\left(\dot{x}_{1}-\dot{x}_{2}\right)=0 \text {. }
$$

Based on the equations of suspension system with one degree of freedom [21-24], the expression of the force $F$ can be expressed as follows:

$$
=8 k\left[\sin ^{2} \phi_{0} x_{2}+\frac{1}{2 l_{0}^{2}}\left(1-6 \sin ^{2} \phi_{0}+5 \sin ^{4} \phi_{0}\right) x_{2}{ }^{3}\right] .
$$

According to the stress analysis diagram of main body (see Figure 1(b)) and expression (2), the equation of main body can be shown as follows:

$$
\begin{aligned}
& m_{2} \ddot{x}_{2}+c_{2} \dot{x}_{2}+8 k\left[a_{0} x_{2}+\left(\frac{b_{0}}{l_{0}^{2}}\right) x_{2}^{3}\right]-k_{1}\left(x_{1}-x_{2}\right) \\
& -c_{1}\left(\dot{x}_{1}-\dot{x}_{2}\right)=0,
\end{aligned}
$$

where $a_{0}=\sin ^{2} \phi_{0}, b_{0}=\left(1-6 \sin ^{2} \phi_{0}+5 \sin ^{4} \phi_{0}\right) / 2$. Integrating (1) with (3), the motion of the suspension system with critical components can be governed by

$$
\begin{aligned}
& m_{1} \ddot{x}_{1}+k_{1}\left(x_{1}-x_{2}\right)+c_{1}\left(\dot{x}_{1}-\dot{x}_{2}\right)=0 \\
& m_{2} \ddot{x}_{2}+c_{2} \dot{x}_{2}+8 k\left[a_{0} x_{2}+\left(\frac{b_{0}}{l_{0}^{2}}\right) x_{2}^{3}\right]-k_{1}\left(x_{1}-x_{2}\right) \\
& -c_{1}\left(\dot{x}_{1}-\dot{x}_{2}\right)=0 .
\end{aligned}
$$

Let the initial conditions of the displacements and the velocity be

$$
\begin{aligned}
& x_{1,2}(0)=0 \\
& \dot{x}_{1,2}(0)=\sqrt{2 g H} .
\end{aligned}
$$

To simplify these equations, dimensionless variables can be introduced as follows: the dimensionless displacements of critical components and main part are $y_{1}=x_{1} / l_{0}$ and $y_{2}=$ $x_{2} / l_{0}$, respectively; the dimensionless time is $\tau=t / T$; the frequency parameters of critical components and main part are $\omega_{1}=\sqrt{k_{1} / m_{1}}$ and $\omega_{2}=\sqrt{8 k / m_{2}}$ separately; the period parameter of main part is $T=1 / \omega_{2}$. The dimensionless 


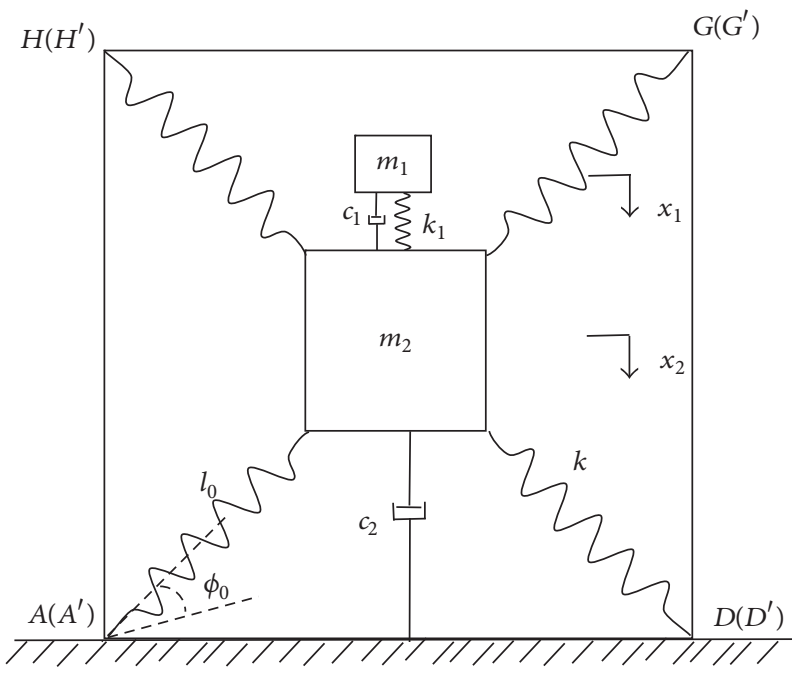

(a)

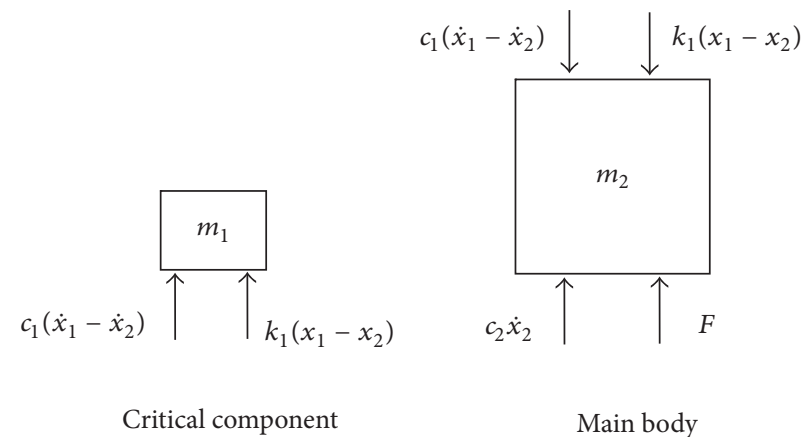

(b)

FIGURE 1: The model and stress analysis diagram of the suspension system with critical components: (a) the model of the suspension system with critical; (b) the stress analysis diagram of the system.

dropping shock dynamic equations for the suspension system can be got as follows:

$$
\begin{aligned}
y_{1}^{\prime \prime} & +\lambda_{2}^{2}\left(y_{1}-y_{2}\right)+2 \zeta_{1} \lambda_{2}\left(y_{1}^{\prime}-y_{2}^{\prime}\right)=0 \\
y_{2}^{\prime \prime} & +2 \zeta_{2} y_{2}^{\prime}+a_{0} y_{2}+b_{0} y_{2}^{3}-\lambda_{1} \lambda_{2}^{2}\left(y_{1}-y_{2}\right) \\
& -2 \zeta_{1} \lambda_{1} \lambda_{2}\left(y_{1}^{\prime}-y_{2}^{\prime}\right)=0 .
\end{aligned}
$$

And the initial conditions for dynamic equations may be expressed as

$$
\begin{aligned}
& y_{1,2}(0)=0 \\
& y_{1,2}^{\prime}(0)=V=\sqrt{\frac{2 g m_{2} H}{8 k l_{0}^{2}}},
\end{aligned}
$$

where $y_{1}^{\prime}=\mathrm{d} y_{1} / \mathrm{d} \tau$ and $y_{2}^{\prime}=\mathrm{d} y_{2} / \mathrm{d} \tau$ are the dimensionless response velocities of critical components and main part, respectively; $y_{1}^{\prime \prime}=\mathrm{d}^{2} y_{1} / \mathrm{d} \tau^{2}$ and $y_{2}^{\prime \prime}=\mathrm{d}^{2} y_{2} / \mathrm{d} \tau^{2}$ are the dimensionless response acceleration of critical components and main part; $\zeta_{1}=c_{1} / 2 \sqrt{k_{1} m_{1}}$ is the damping ratio between critical components and main part; $\zeta_{2}=c_{2} / 2 \sqrt{8 \mathrm{~km}}$ is the damping ratio of the suspension system; $\lambda_{1}=m_{1} / m_{2}$ is the system mass ratio; $\lambda_{2}=\omega_{1} / \omega_{2}$ is the suspension system frequency ratio, separately.

\section{Dimensionless Displacement Response}

According to (6), the numerical analysis was obtained by using the fourth-order Runge-Kutta method, and the dropping shock response characteristics of critical components were studied.

3.1. The Influence of Frequency Ratio. Figure 2(a) depicts the displacement response of critical components with different frequency ratios, when the suspension angle $\phi_{0}=60^{\circ}$, the mass ratio $\lambda_{1}=0.05$, the damping ratios $\zeta_{1}=\zeta_{2}=0.1$, and dimensionless shock velocity $V=0.3$.

3.2. The Influence of System Damping Ratio. Figure 2(b) shows the displacement response of critical components with different damping ratios $\zeta_{2}$, based on the suspension angle $\phi_{0}=60^{\circ}$, the mass ratio $\lambda_{1}=0.05$, the damping ratio $\zeta_{1}=0.1$, the frequency ratio $\lambda_{2}=5$, and dimensionless shock velocity $V=0.3$.

3.3. The Influence of Damping Ratio between the Critical Components and the Body. The displacement response of critical components with different damping ratios $\zeta_{1}$ is revealed in Figure 2(c), when the suspension angle $\phi_{0}=60^{\circ}$, the mass ratio $\lambda_{1}=0.05$, the damping ratio $\zeta_{2}=0.1$, the frequency ratio $\lambda_{2}=5$, and dimensionless shock velocity $V=0.3$.

3.4. The Influence of Suspension Angle. Figure 2(d) illustrates the displacement response of critical components with different suspension angles, when the mass ratio $\lambda_{1}=0.05$, the damping ratio $\zeta_{1}=\zeta_{2}=0.1$, the frequency ratio $\lambda_{2}=5$, and dimensionless shock velocity $V=0.3$.

3.5. The Influence of Dimensionless Shock Velocity. Figure 2(e) illustrates the displacement response of critical components with different dimensionless shock velocities, when the suspension angle $\phi_{0}=60^{\circ}$, the damping ratio $\zeta_{1}=\zeta_{2}=0.1$, the mass ratio $\lambda_{1}=0.05$, and the frequency ratio $\lambda_{2}=5$.

\section{Dimensionless Acceleration Response}

4.1. The Influence of Frequency Ratio. Figure 3(a) depicts the acceleration response of critical components with different frequency ratios, to get the results; let the suspension angle $\phi_{0}=60^{\circ}$, the mass ratio $\lambda_{1}=0.05$, the damping ratio $\zeta_{1}=$ $\zeta_{2}=0.1$, and dimensionless shock velocity $V=0.3$. 

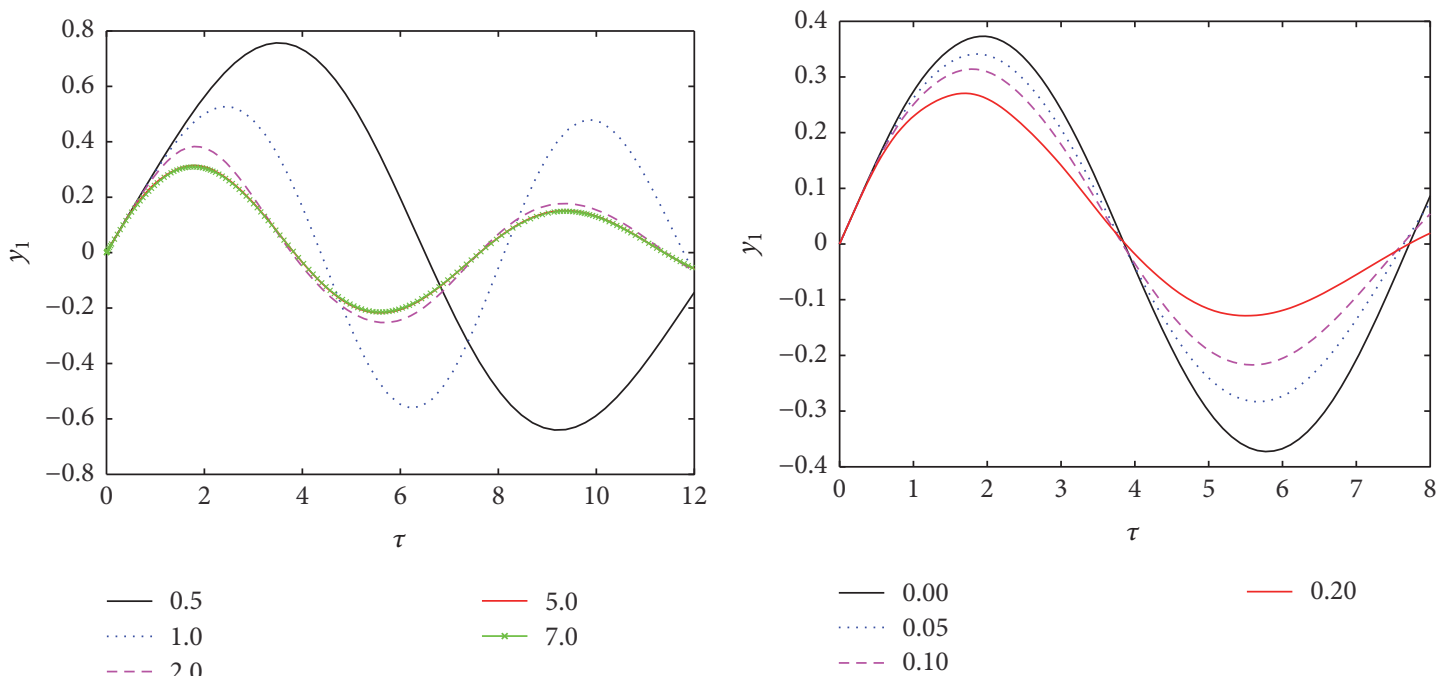

(a) $\lambda_{2}=0.5,1,3,5,7$

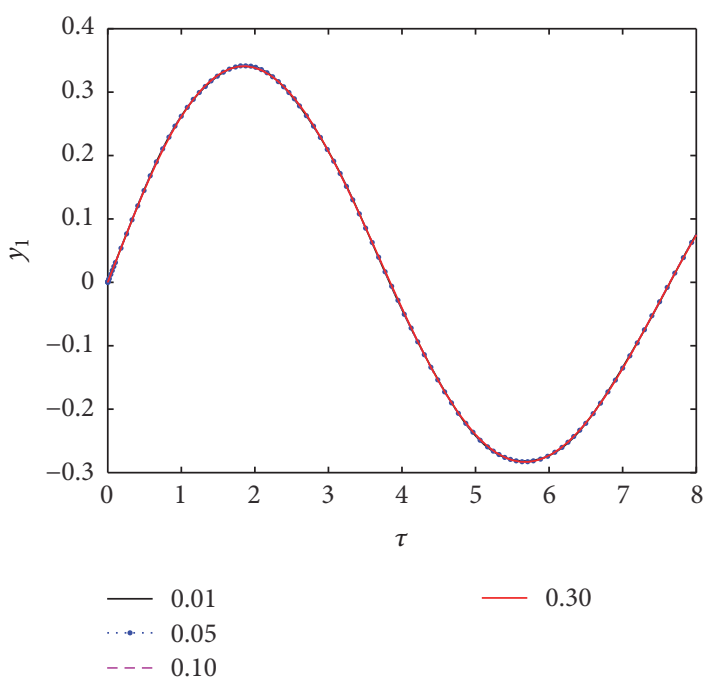

(c) $\zeta_{1}=0.01,0.05,0.1,0.3$

(b) $\zeta_{2}=0,0.05,0.1,0.2$
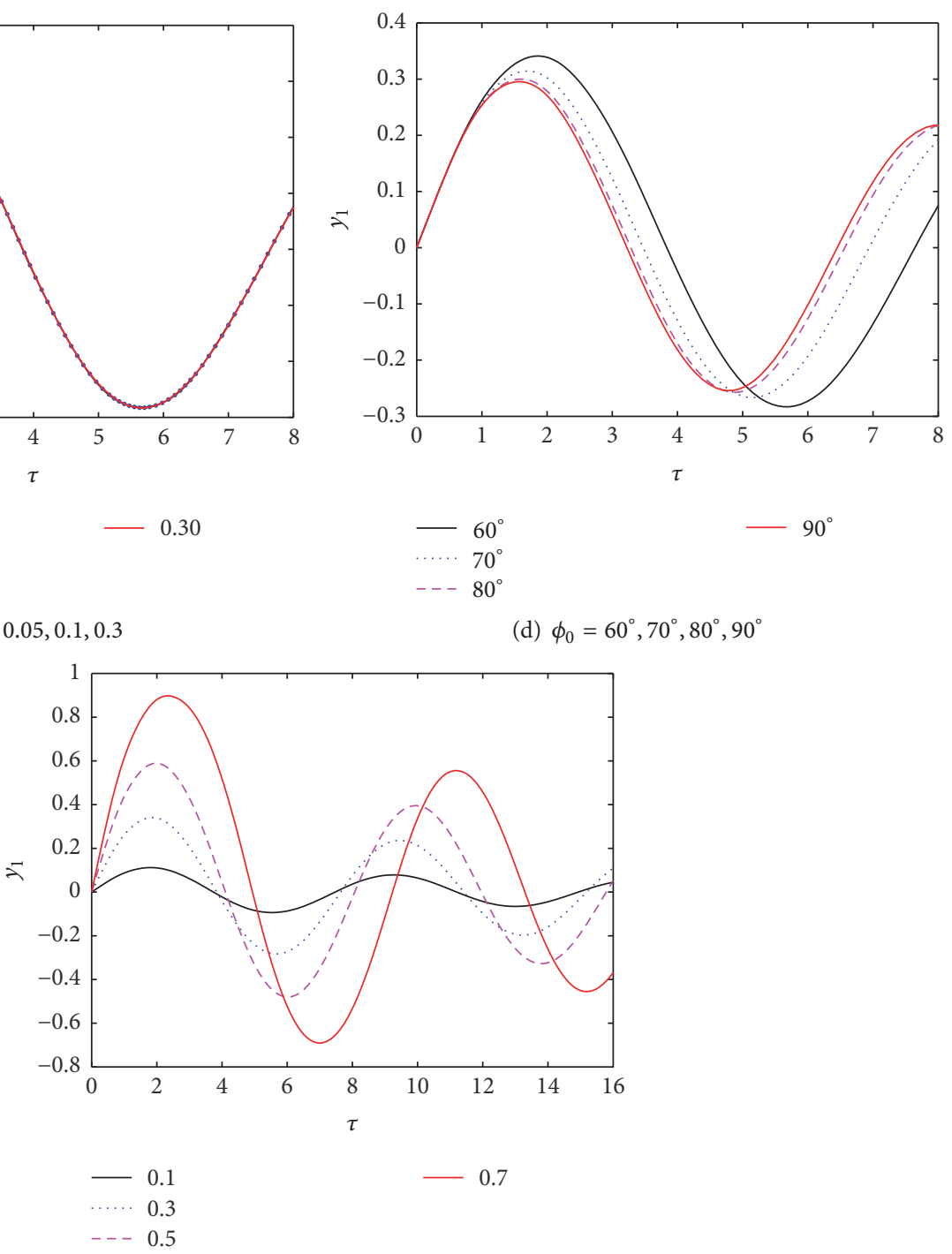

(e) $V=0.1,0.3,0.5,0.7$

FIgURE 2: The displacement response for different parameters. 

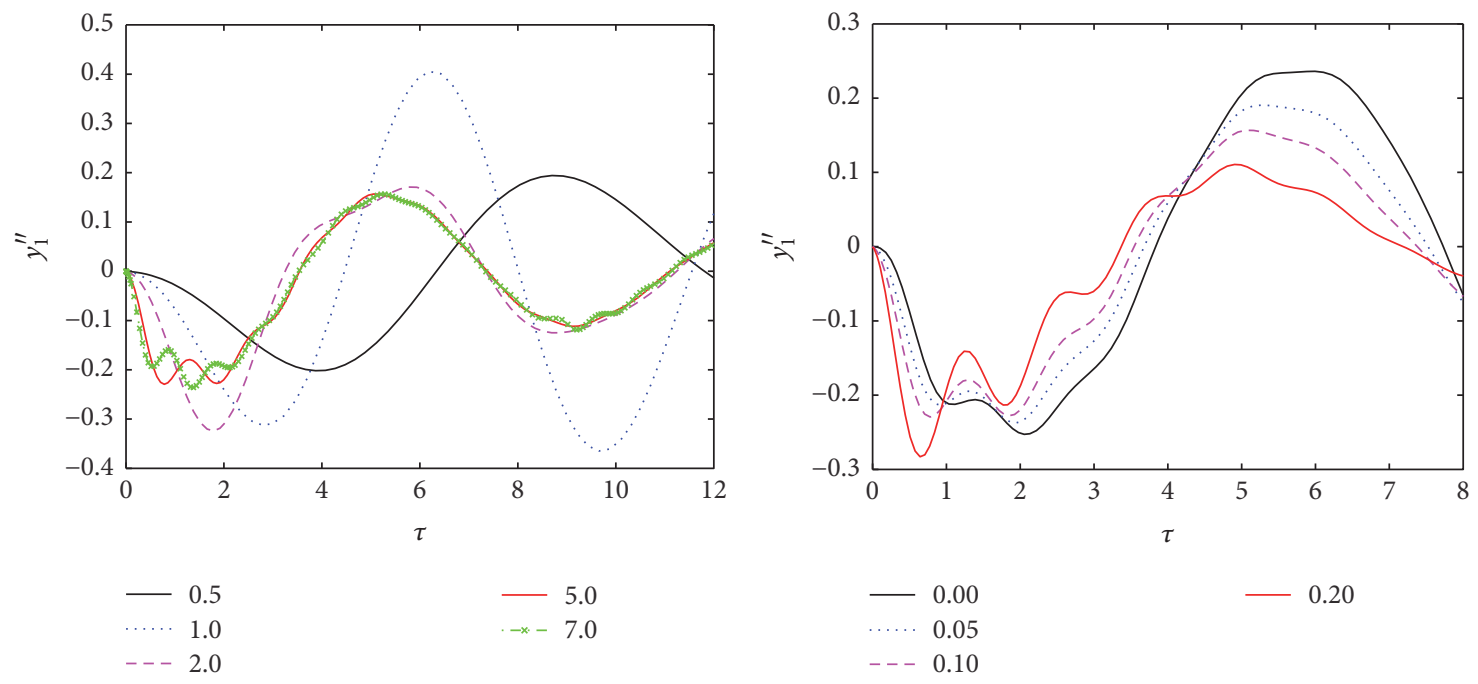

(a) $\lambda_{2}=0.5,1,3,5,7$

(b) $\zeta_{2}=0,0.05,0.1,0.2$
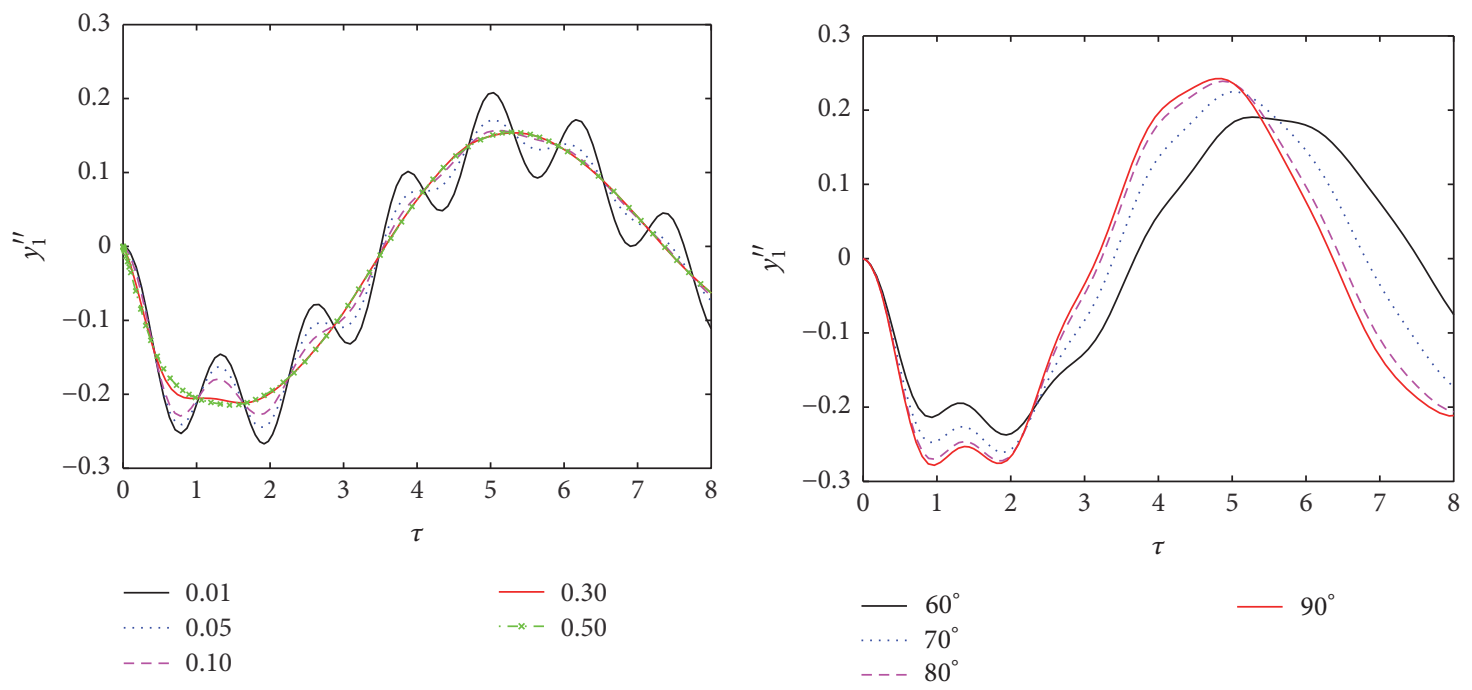

(c) $\zeta_{1}=0.01,0.05,0.1,0.3$

(d) $\phi_{0}=60^{\circ}, 70^{\circ}, 80^{\circ}, 90^{\circ}$
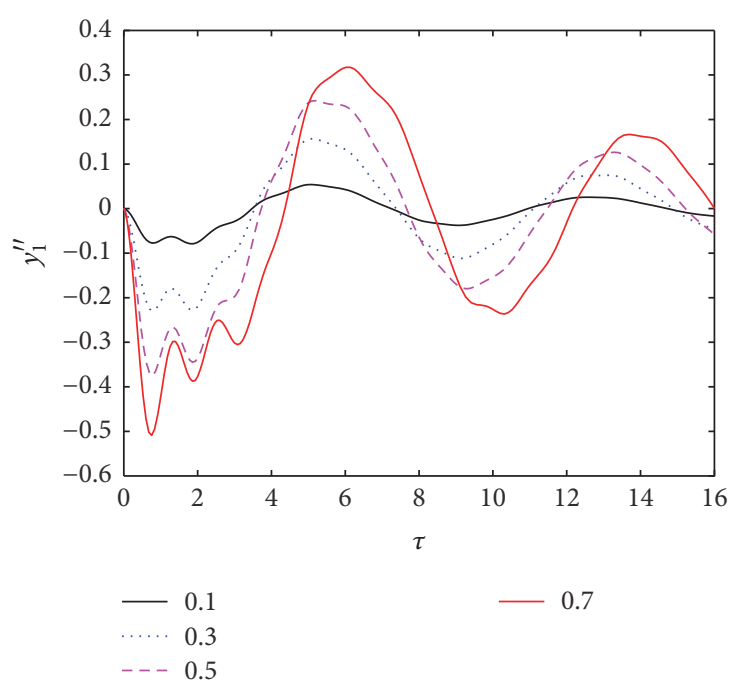

(e) $V=0.1,0.3,0.5,0.7$

FIGURE 3: The acceleration response for different parameters. 


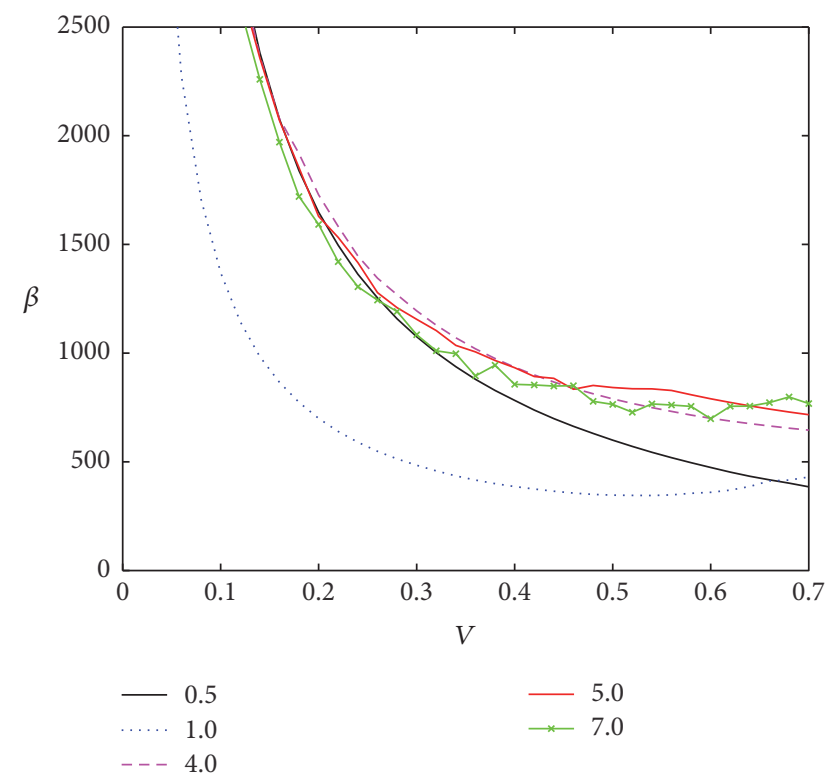

(a) $\zeta_{2}=0$

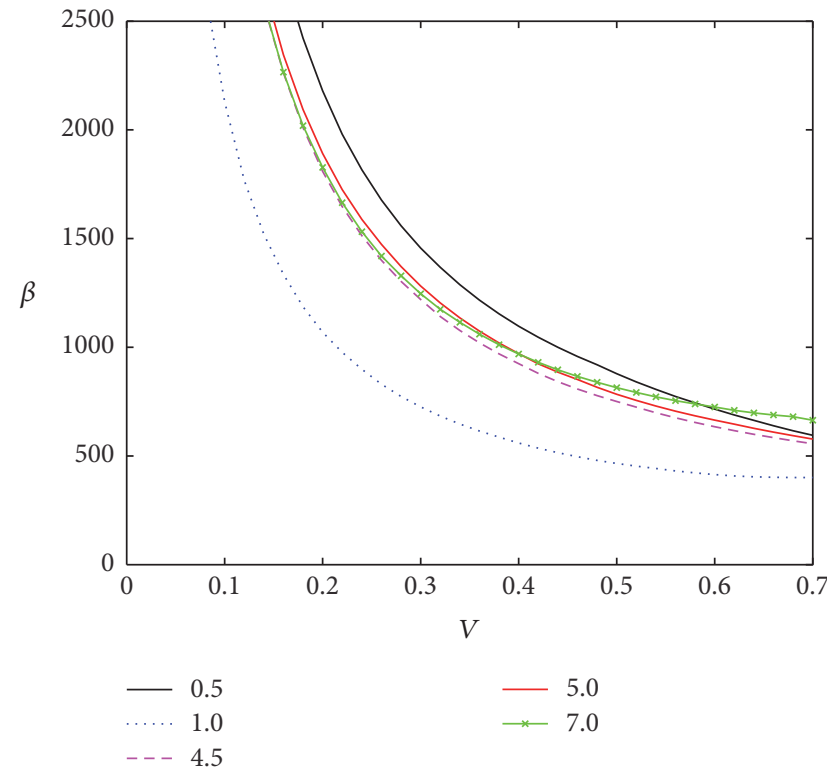

(c) $\zeta_{2}=0.1$

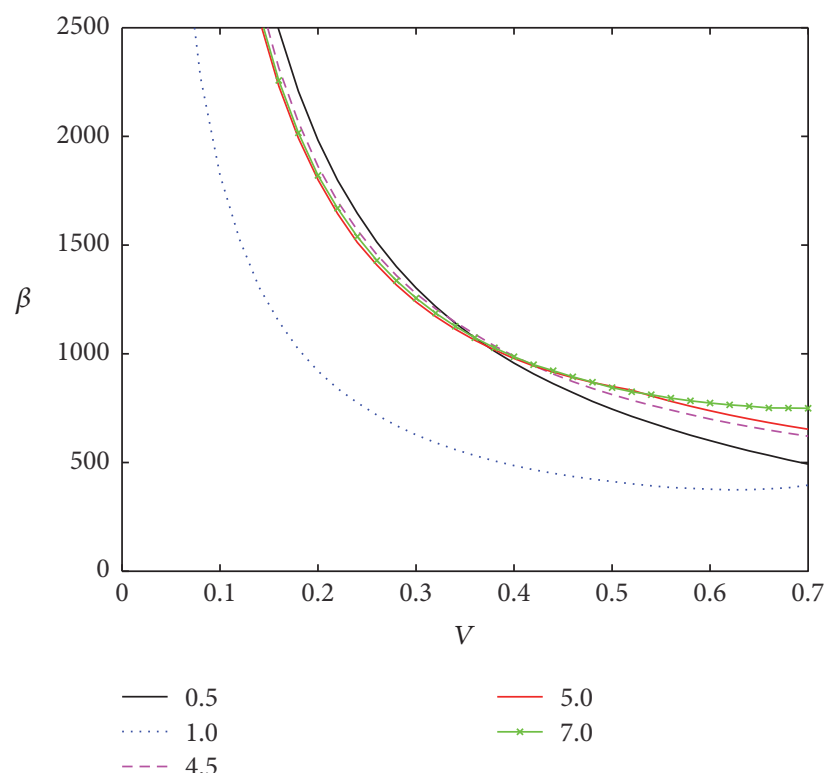

(b) $\zeta_{2}=0.05$

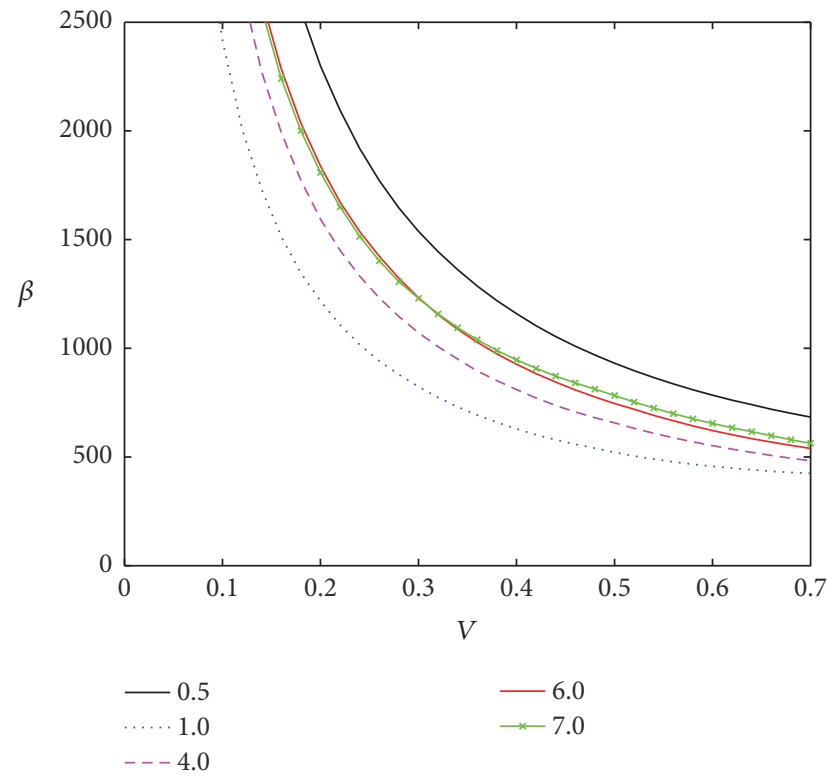

(d) $\zeta_{2}=0.15$

FIgURE 4: Dropping damage boundary curves for different damping ratio $\zeta_{2}$. Here, $\lambda_{1}=0.05, \zeta_{1}=0.1, \phi_{0}=60^{\circ}, A_{c}=30$.

4.2. The Influence of System Damping Ratio. Figure 3(b) shows the acceleration response of critical components with different damping ratios $\zeta_{2}$, when we set the suspension angle $\phi_{0}=60^{\circ}$, the mass ratio $\lambda_{1}=0.05$, the damping ratio $\zeta_{1}=0.1$, the frequency ratio $\lambda_{2}=5$ and dimensionless shock velocity $V=0.3$.

4.3. The Influence of Damping Ratio between the Critical Components and the Body. Figure 3(c) conveys the acceleration response of critical components with different damping ratios $\zeta_{1}$, when we choose the suspension angle $\phi_{0}=60^{\circ}$, the mass ratio $\lambda_{1}=0.05$, the damping ratio $\zeta_{2}=0.05$, the frequency ratio $\lambda_{2}=5$, and dimensionless shock velocity $V=0.3$.
4.4. The Influence of Suspension Angle. Figure 3(d) illustrates the acceleration response of critical components with different suspension angles, based on the mass ratio $\lambda_{1}=0.05$, the damping ratio $\zeta_{1}=\zeta_{2}=0.1$, the frequency ratio $\lambda_{2}=5$, and dimensionless shock velocity $V=0.3$.

4.5. The Influence of Dimensionless Shock Velocity. Figure 3(e) performs the acceleration response of critical components with different dimensionless shock velocities, under the conditions of the suspension angle $\phi_{0}=60^{\circ}$, the mass ratio $\lambda_{1}=0.05$, the damping ratio $\zeta_{1}=\zeta_{2}=0.1$, and frequency ratio $\lambda_{2}=5$. 


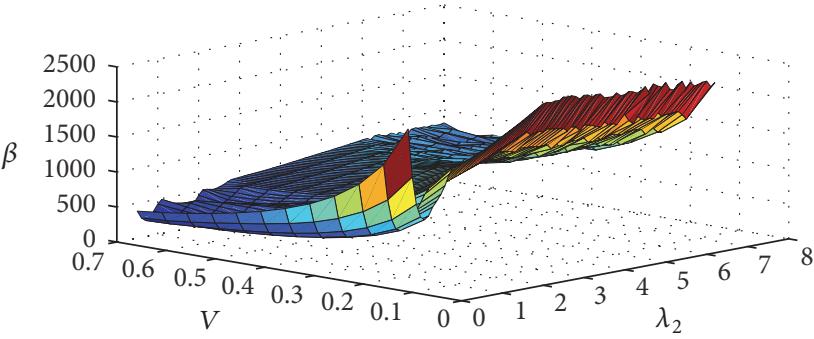

(a) $\zeta_{2}=0$

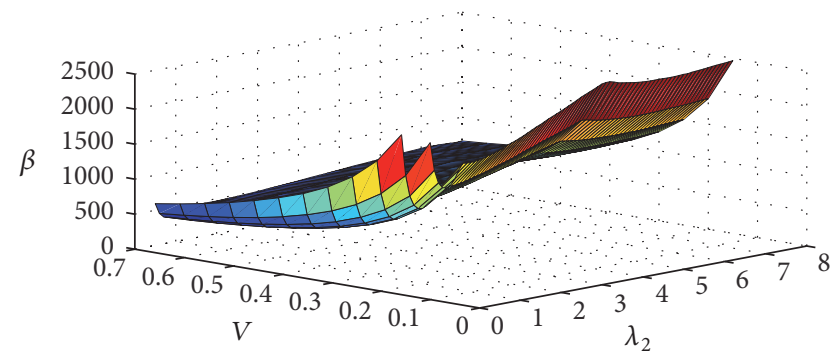

(c) $\zeta_{2}=0.1$

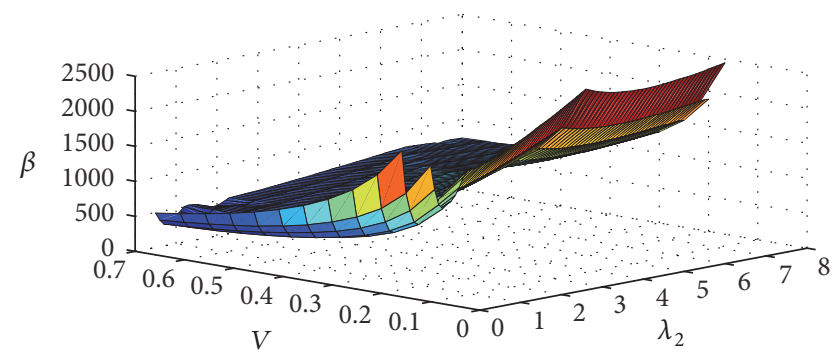

(b) $\zeta_{2}=0.05$

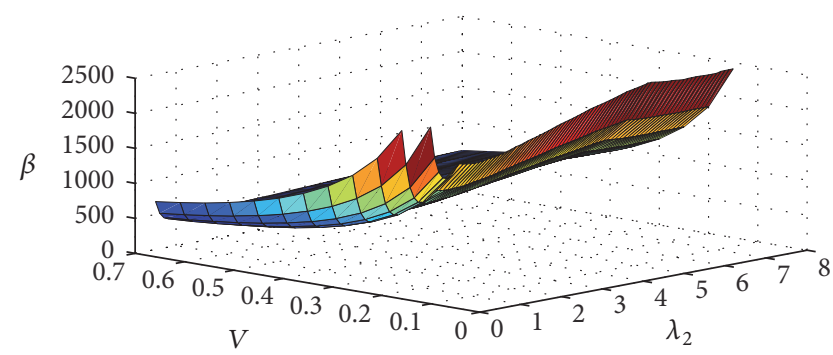

(d) $\zeta_{2}=0.15$

FIGURE 5: Dropping damage boundary surfaces for different damping ratio $\zeta_{2}$. Here, $\lambda_{1}=0.05, \zeta_{1}=0.1, \phi_{0}=60^{\circ}, A_{c}=30$.

\section{Dropping Damage Evaluation}

The concept of dropping damage boundary curve was presented [6], based on which the dropping damage boundary curve of the suspension system with two degrees of freedom can be derived.

The Runge-Kutta method can be used to solve the nonlinear equations (6); then the dimensionless maximum acceleration $y_{1 m}^{\prime \prime}$ can be derived. Set $A_{c}$ as the fragility of the critical components, and the critical components are destroyed, if the maximum response acceleration meets the requirements:

$$
\ddot{x}_{1 m}=\left(\frac{\mathrm{d}^{2} x_{1}}{\mathrm{~d} t^{2}}\right)_{m}>A_{c} g,
$$

where $g$ is gravity acceleration. Let

$$
\left(\frac{\mathrm{d}^{2} x_{1}}{\mathrm{~d} t^{2}}\right)_{m}=\beta\left(\frac{\mathrm{d}^{2} y_{1}}{\mathrm{~d} \tau^{2}}\right)_{m}=A_{c} g,
$$

where the system parameter $\beta=l_{0} / T^{2}=8 k l_{0} / m_{2}$. The relational expression can be also written as

$$
\beta=\frac{A_{c} g}{y_{1 m}^{\prime \prime}} .
$$

According to (6), the dimensionless maximum acceleration $y_{1 m}^{\prime \prime}$ is related to the suspension angle, the frequency ratio, the damping ratios $\zeta_{1}$ and $\zeta_{2}$, and the dimensionless shock velocity. Integrating the dimensionless maximum acceleration $y_{1 m}^{\prime \prime}$ with (10), the dropping damage boundary curves were established, the two coordinate parameters of which are composed of the dimensionless dropping shock velocity $V$ and the system parameter $\beta$.
5.1. The Influence of Frequency Ratio. The dropping damage boundary curves of critical components are shown in Figure 4 . Next, the frequency ratio $\lambda_{2}$ is set as third coordinate parameter; the dropping damage boundary surfaces of critical components are derived in Figure 5.

5.2. The Influence of System Damping Ratio. The dropping damage boundary curves of critical components are shown in Figure 6. Then, we choose the damping ratio $\zeta_{2}$ as third coordinate parameter, and the dropping damage boundary surfaces of critical components are derived in Figure 7.

5.3. The Influence of Damping Ratio between the Critical Components and the Main Body. To discuss the influence of damping ratio between the critical components and the main body, the dropping damage boundary curves of critical components are shown in Figure 8. Selecting the frequency ratio as third coordinate parameter, and the dropping damage boundary surfaces of critical components are graphed in Figure 9.

5.4. The Influence of Suspension Angle. The dropping damage boundary curves of critical components are shown in Figure 10. Consider the frequency ratio as third coordinate parameter, and the dropping damage boundary surfaces of critical components are presented in Figure 11.

\section{Discussion}

6.1. The Influences of the Frequency Ratio. Figures 2(a), 3(a), 4 , and 5 show that the dynamic characteristics of critical components are sensitive to the frequency ratio, and increasing the frequency ratio can decrease the displacement response peak (Figure 2(a)). Furthermore, a small value of frequency ratio $\left(\lambda_{2}<5\right)$ can generate fluctuation of the maximum 


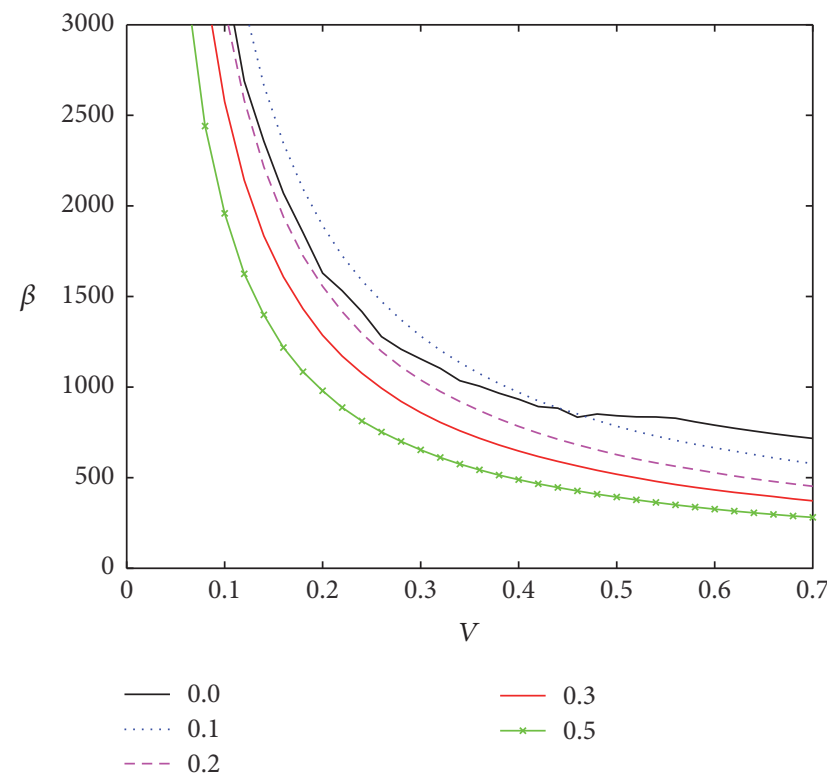

(a) $\lambda_{2}=5$

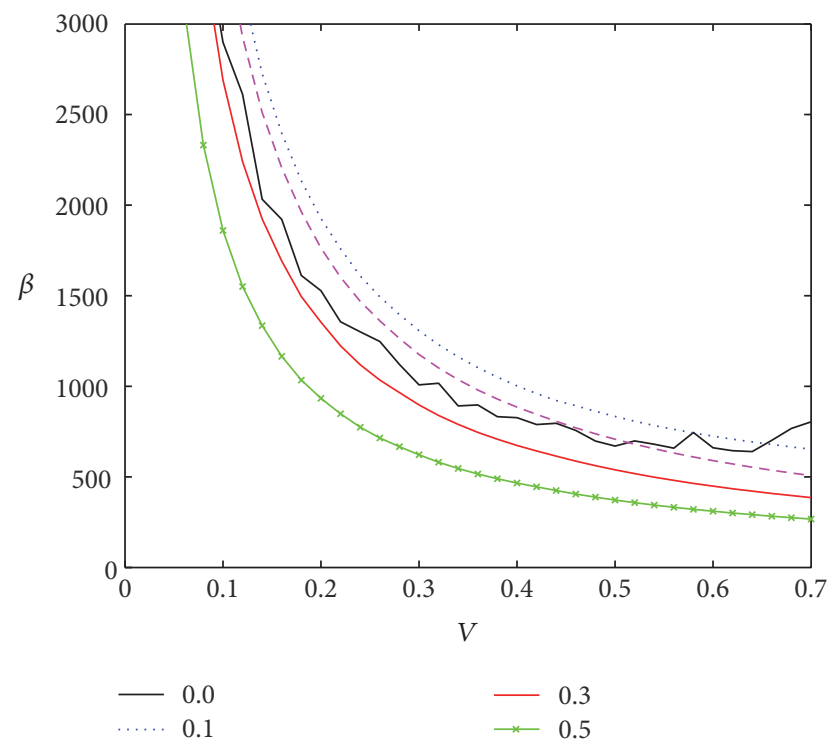

(c) $\lambda_{2}=9$

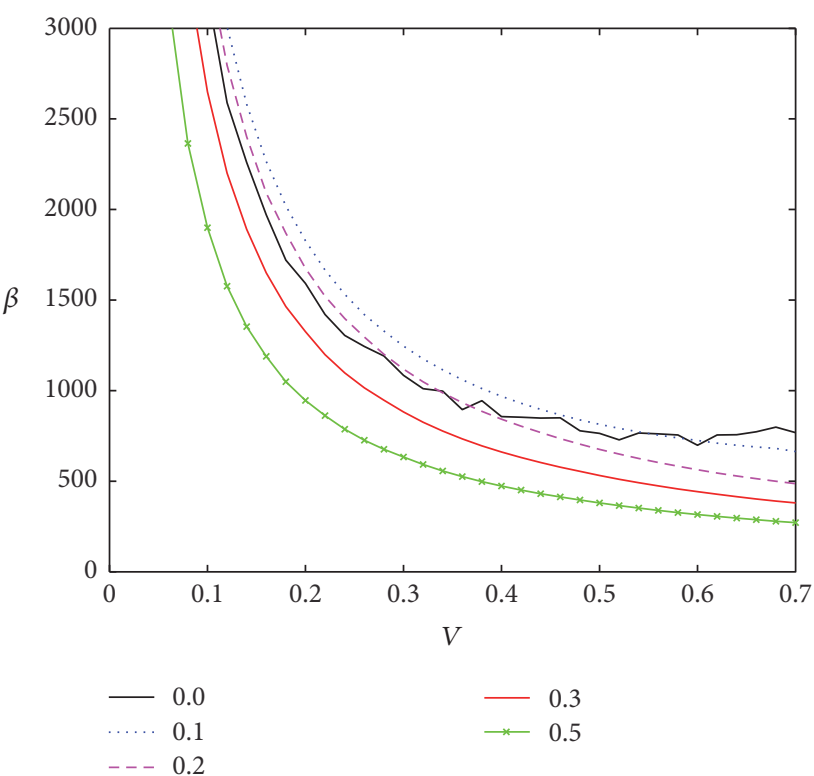

(b) $\lambda_{2}=7$

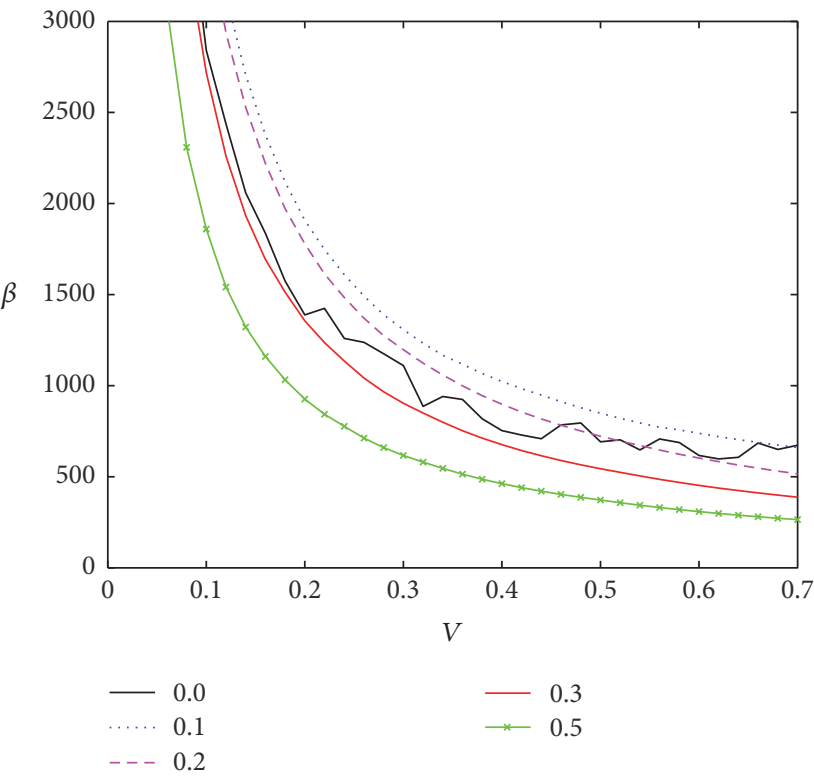

(d) $\lambda_{2}=10$

Figure 6: Dropping damage boundary curves for different frequency ratio $\lambda_{2}$. Here, $\lambda_{1}=0.05, \zeta_{1}=0.1, \phi_{0}=60^{\circ}, A_{c}=30$.

acceleration response values and the safety zone, where the critical components is more easily damaged. Correspondingly, a high frequency ratio value $\left(\lambda_{2}>5\right)$ can reduce the maximum acceleration response values and enlarge safety zone obviously (Figures 3(a), 4, and 5). In summary, the high frequency ratio value $\left(\lambda_{2}>5\right)$ can improve the protection performance of the product.

6.2. The Influences of the System Damping Ratio $\zeta_{2}$. According to Figures 2(b), 3(b), 6, and 7, we observed that the suspension system damping ratio is another sensitive parameter of dynamic characteristics for critical components, and the displacement response peak decreases along with the increase of system damping ratio (Figure 2(b)). For the acceleration response peak and the safety zone of critical components, there exists the best damping ratio $\left(\zeta_{2}=0.1\right)$. That is, when the system damping ratio $\zeta_{2}=0.1$, the acceleration response peak reaches the minimum value (Figure $3(\mathrm{~b})$ ) and the safety zone reaches the maximum value (Figure 6). Further research showed that the precise value of the best damping ratio varies depending on the frequency ratio (Figure 7). Thus, when the values of relevant parameters are uncertain, we cannot get the exact value of the best damping ratio. To summarize, it is not a wise choice to increase the system damping ratio value as far 


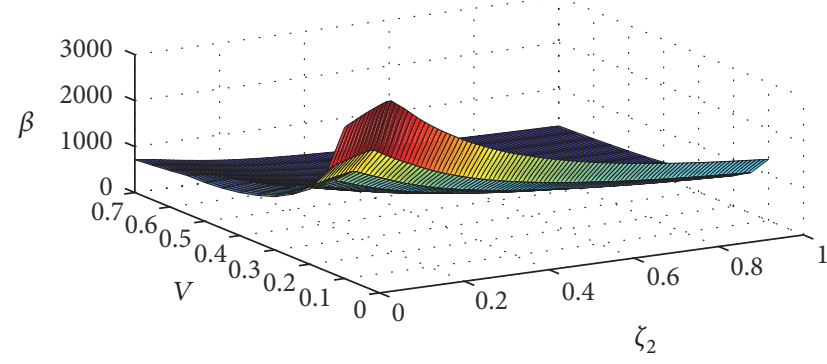

(a) $\lambda_{2}=5$

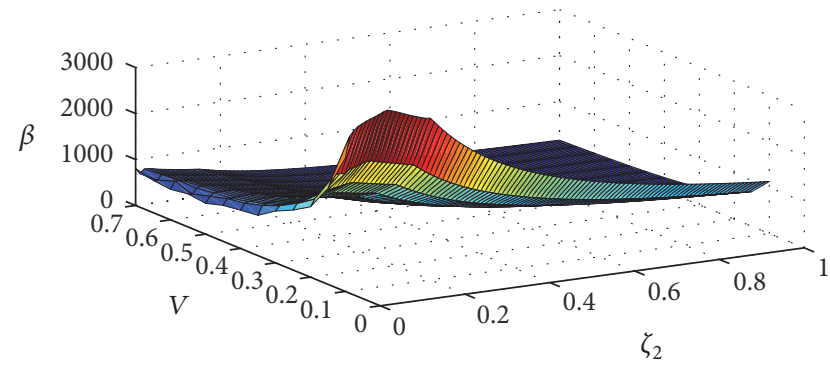

(c) $\lambda_{2}=9$

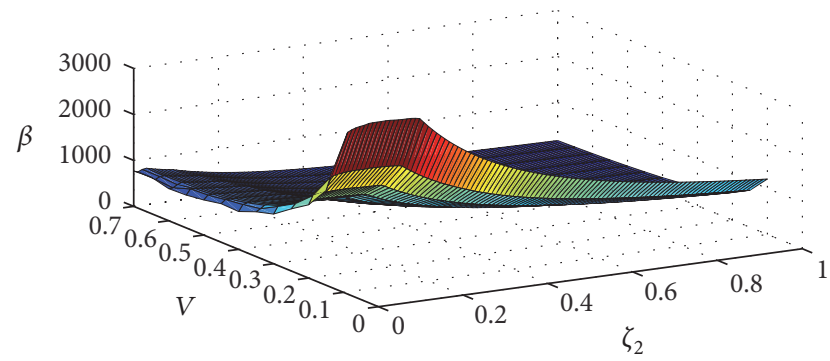

(b) $\lambda_{2}=7$

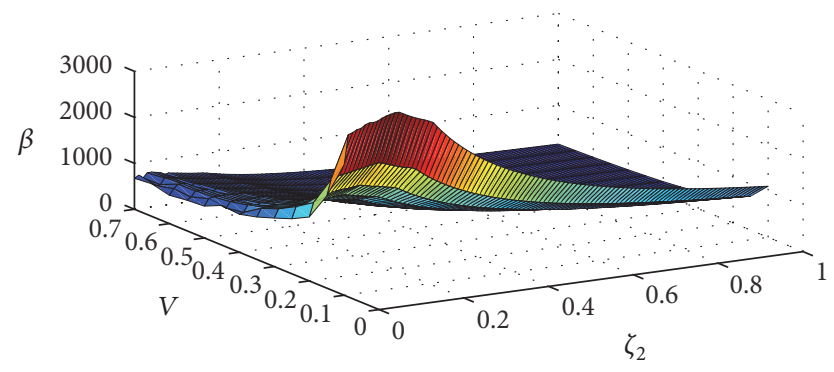

(d) $\lambda_{2}=10$

FIgURE 7: Dropping damage boundary surfaces for different frequency ratio $\lambda_{2}$. Here, $\lambda_{1}=0.05, \zeta_{1}=0.1, \phi_{0}=60^{\circ}, A_{c}=30$.

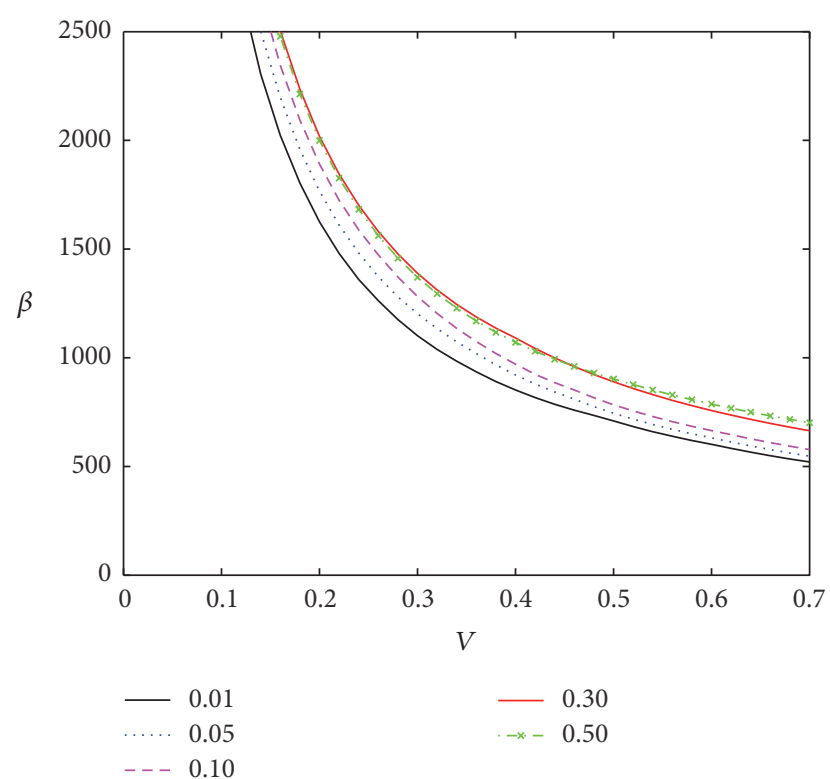

FIGURE 8: Dropping damage boundary curves with different damping ratio $\zeta_{1}$. Here, $\lambda_{1}=0.05, \zeta_{2}=0.1, \phi_{0}=60^{\circ}, \lambda_{2}=5, A_{c}=30$.

as possible in the design procedure of cushioning packaging, and the system damping ratios in the specific range can exert a positive effect on the product protection.

6.3. The Influences of the Damping Ratio $\zeta_{1}$ between Critical Components and Main Body. From Figures 2(c), 3(c), 8, and 9 , we found that the influence of damping ratio $\zeta_{1}$ on the response peak of displacement is not noticeable (Figure 2(c)). On the contrary, it is obvious that increasing the damping ratio can decrease the response peak of acceleration and enlarge safety zone. However, when damping ratio $\zeta_{1}>0.3$, the change of acceleration response peak is not significant with the damping ratio $\zeta_{1}$ increasing (Figures $3(\mathrm{c}), 8$, and 9 ). Hence, the protection performance of the suspension system should be improved by increasing the damping ratio $\zeta_{1}$ suitably.

6.4. The Influences of the Suspension Angle. On the basis of the numerical results of Figures 2(d), 3(d), 10, and 11, it is demonstrated that decreasing suspension angle can reduce the acceleration response peak and enlarge the safety area (Figures $3(\mathrm{c}), 10$, and 11). However, note that decreasing the suspension angle can also increase the displacement response peak and expend the response period (Figure 2(d)), and the increase of displacement response peak may exceed the maximum deformation of the suspension spring. In summary, within the maximum compression range of the suspension springs, the decrease in the suspension angle can benefit the product protection. The results indicate that the geometrical nonlinearity system performs better than the linear system $\left(\phi_{0}=\right.$ $90^{\circ}$ ) on buffering performance.

6.5. The Influences of the Dimensionless Shock Velocity. It is shown in Figures 2(e) and 3(e) that the system acceleration and displacement responses increase and the period is expended closely along with an augment of dimensionless velocity. Surprisingly, we found that (7) can reveal the relationship between the dimensionless shock velocity and relevant parameters clearly. By the analysis of the equation $V=\sqrt{2 m_{2} g H / 8 k l_{0}^{2}}$, we can decrease the dimensionless response velocity through increasing the original length of the suspension springs, increasing the stiffness coefficient of the 


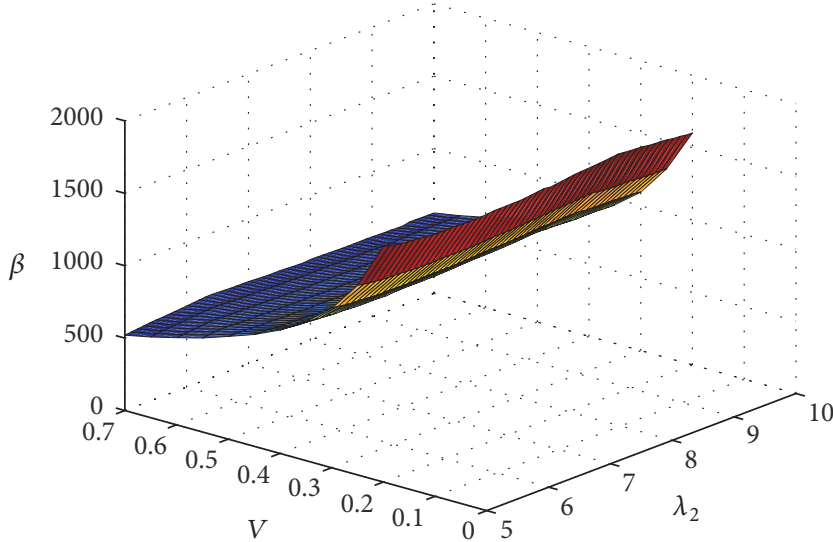

(a) $\zeta_{1}=0.01$

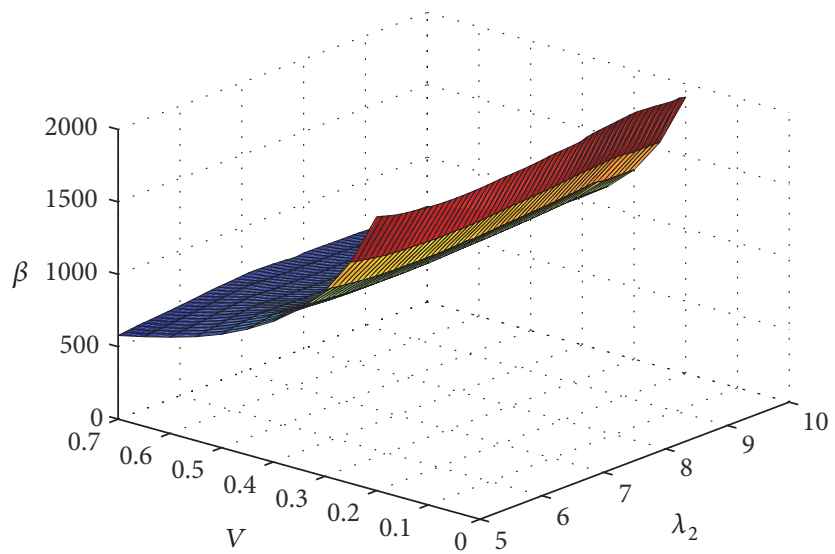

(c) $\zeta_{1}=0.1$

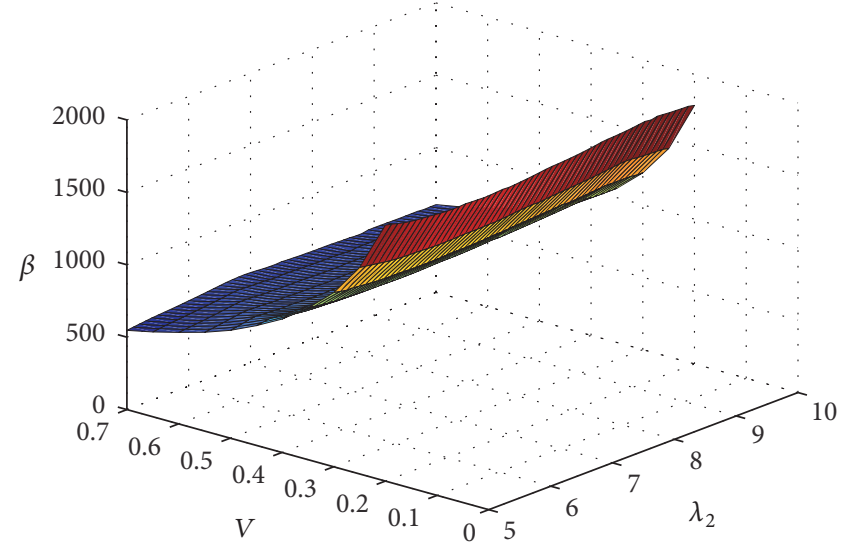

(b) $\zeta_{1}=0.05$

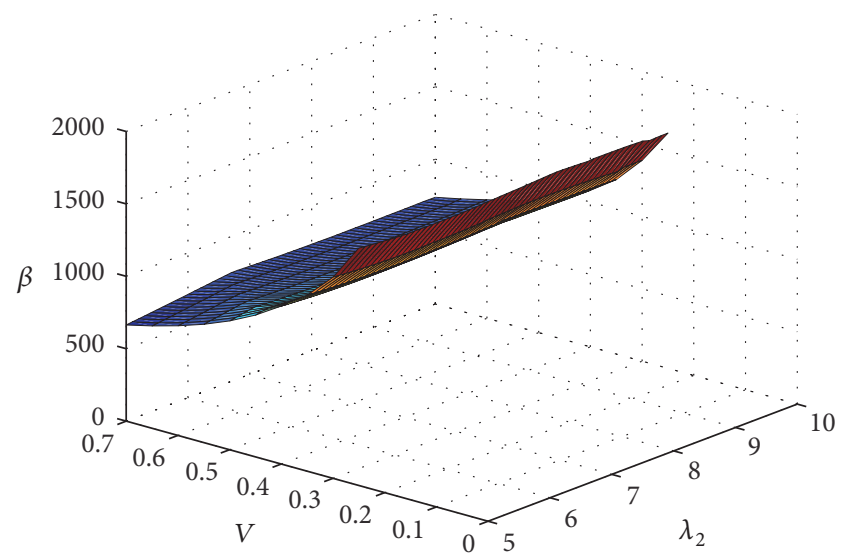

(d) $\zeta_{1}=0.03$

FIGURE 9: Dropping damage boundary surfaces for different damping ratio $\zeta_{1}$. Here, $\lambda_{1}=0.05, \zeta_{2}=0.1, \phi_{0}=60^{\circ}, A_{c}=30$.

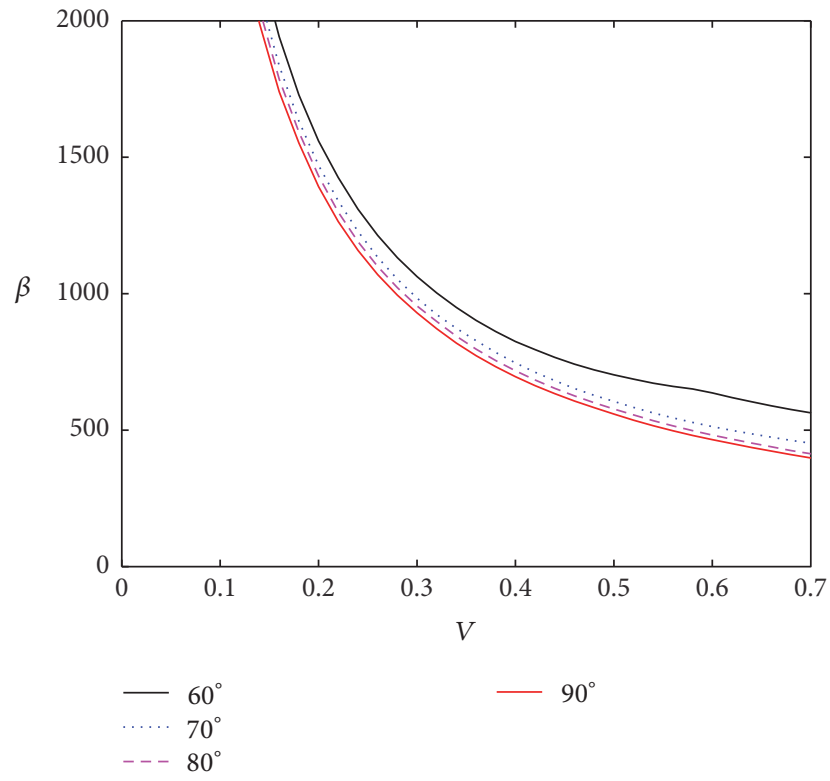

FIGURE 10: Dropping damage boundary curves with different suspension angle $\phi_{0}$. Here, $\lambda_{1}=0.05, \zeta_{1}=\zeta_{2}=0.1, \lambda_{2}=5, A_{c}=30$. suspension springs and/or decreasing the dropping height. The results indicate that the dropping shock velocity should be reduced as much as possible by changing the value of relevant parameters in the product protection.

For the real suspension packaging system, the simplified models were established by some authors [20-24]. To improve the present models, this paper took the critical component into account and derived the two-degree-offreedom system. The new models of suspension system contain eight inclined linear springs, and (2) reveals that the relation between the resilience and the distortion presents nonlinear property, that is, geometric nonlinearity. However, the models of suspension packaging system will be more realistic to include nonlinear constitutive relations for the spring and damper and need to be further studied. Even so, the results provide us with a good reference to design the real suspension packaging system.

\section{Conclusion}

The aim of this paper is to derive the governing equations of two-degree-of-freedom suspension system and discuss the 


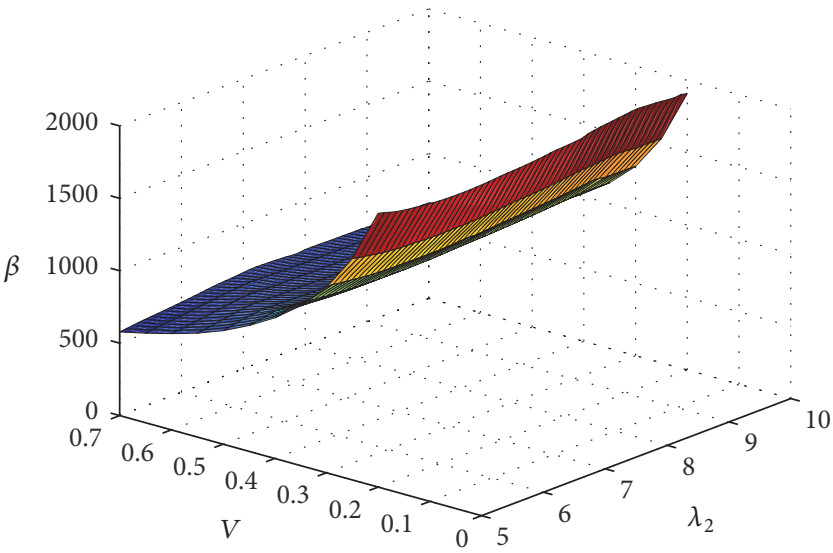

(a) $\phi_{0}=60^{\circ}$

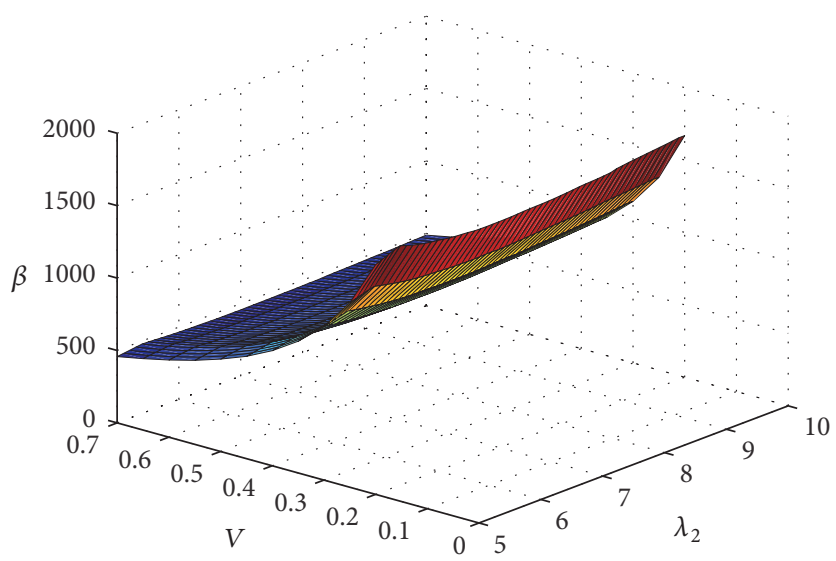

(c) $\phi_{0}=80^{\circ}$

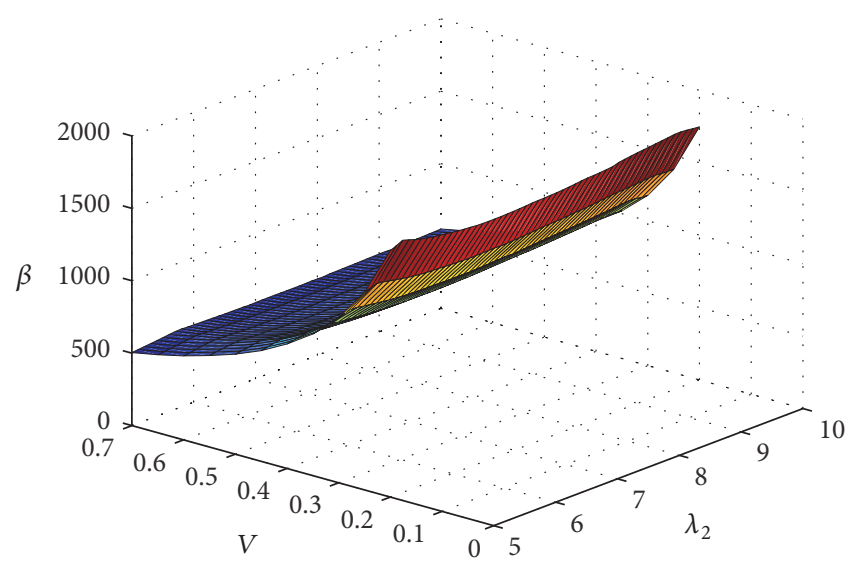

(b) $\phi_{0}=70^{\circ}$

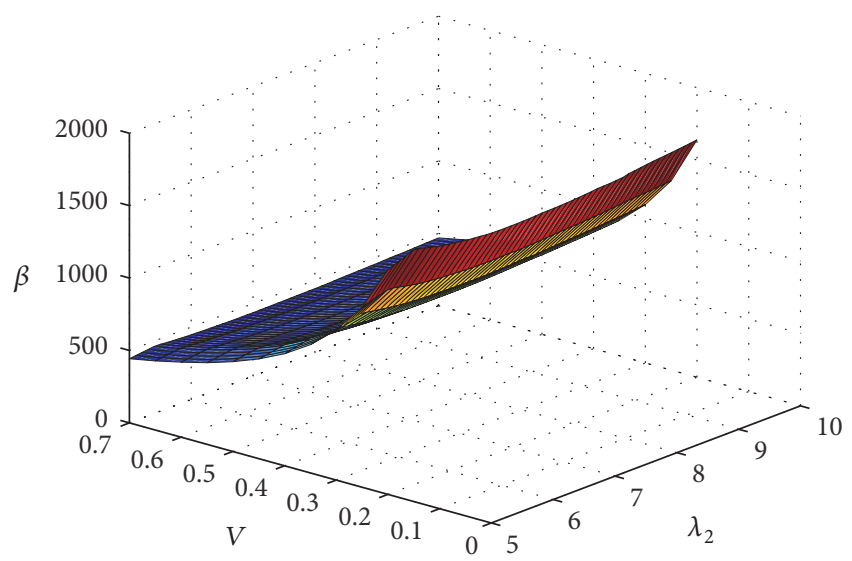

(d) $\phi_{0}=90^{\circ}$

FIGURE 11: The dropping damage boundary surfaces for different suspension angle $\phi_{0}$. Here, $\lambda_{1}=0.05, \zeta_{1}=\zeta_{2}=0.1, A_{c}=30$.

influences of the frequency ratio, the system damping ratio, the suspension angle, and the damping ratio between critical components and the product on dynamic characteristics of this system. Summing up the results, it is shown that the dynamic characteristics of the suspension system are sensitive to the frequency ratio, the system damping ratio, and the suspension angle. First, when the values of frequency ratio are more than five, the maximum shock response value can reduce and the safety zone can enlarge obviously. Next, it is shown that when a system damping ratio value falls in a specific range, the performance in the product protection can be improved remarkably. Furthermore, compared with linear system, a low suspension angle can benefit the product protection relatively. The results can provide a guideline for the design process of the suspension packaging system.

\section{Conflicts of Interest}

The authors declare that there are no conflicts of interest regarding the publication of this paper.

\section{References}

[1] R. D. Mindlin, "Dynamics of Package Cushioning," Bell System Technical Journal, vol. 24, no. 3, pp. 353-461, 1945.
[2] R. E. Newton, Fragility Assessment Thory and Practice, Monterey Research Laboratory, Monterey, Calif, USA, 1968.

[3] G. J. Burgess, "Product fragility and damage boundary theory," Packaging Technology and Science, vol. 1, no. 1, pp. 5-10, 1988.

[4] G. J. Burgess, "Effects of fatigue on fragility testing and the damage boundary curve," Journal of Testing and Evaluation, vol. 24, no. 6, pp. 419-426, 1996.

[5] Z. Wang, C. Wu, and D. Xi, "Damage boundary of a packaging system under rectangular pulse excitation," Packaging Technology and Science, vol. 11, no. 4, pp. 189-202, 1998.

[6] Z. Wang, "On evaluation of product dropping damage," Packaging Technology and Science, vol. 15, no. 3, pp. 115-120, 2002.

[7] C. Zhong, K. Saito, and K. Kawaguchi, "Improvement of equivalent drop theory for transport packaging," Packaging Technology and Science, vol. 26, no. 2, pp. 67-81, 2013.

[8] C. Zhong, K. Saito, K. Kawaguchi, and H. Setoue, "The hybrid drop test," Packaging Technology and Science, vol. 27, no. 7, pp. 509-520, 2014.

[9] H. Kitazawa, K. Saito, and Y. Ishikawa, "Effect of difference in acceleration and velocity change on product damage due to repetitive shock," Packaging Technology and Science, vol. 27, no. 3, pp. 221-230, 2014.

[10] A.-J. Chen, "Application of variational iteration method with energy method for nonlinear equation arisen from packaging 
system," Mathematical Problems in Engineering, vol. 2013, Article ID 326239, 5 pages, 2013.

[11] A.-J. Chen, "Ren-He's method for solving dropping shock response of nonlinear packaging system," Advances in Difference Equations, vol. 2016, no. 1, article no. 279, 2016.

[12] A.-J. Chen, "Resonance analysis for tilted support spring coupled nonlinear packaging system applying variational iteration method," Mathematical Problems in Engineering, vol. 2013, Article ID 384251, 4 pages, 2013.

[13] J. Wang, J. Jiang, L. Lu, and Z. Wang, "Dropping damage evaluation for a tangent nonlinear system with a critical component," Computers \& Mathematics with Applications, vol. 61, no. 8, pp. 1979-1982, 2011.

[14] Z.-W. Wang and J.-H. Jiang, "Evaluation of product dropping damage based on key component," Packaging Technology and Science, vol. 23, no. 4, pp. 227-238, 2010.

[15] J.-H. Jiang and Z.-W. Wang, "Dropping damage boundary curves for cubic and hyperbolic tangent packaging systems based on key component," Packaging Technology and Science, vol. 25, no. 7, pp. 397-411, 2012.

[16] J. Wang, F. Duan, J. Jiang, L. Lu, and Z. Wang, "Dropping damage evaluation for a hyperbolic tangent cushioning system with a critical component," Journal of Vibration and Control, vol. 18, no. 10, pp. 1417-1421, 2012.

[17] A.-J. Chen, "The shock characteristics of tilted support spring packaging system with critical components," Shock and Vibration, vol. 2014, Article ID 496035, 8 pages, 2014.

[18] N. Duan, M. Hao, and A. Chen, "Damage evaluation of critical components of tilted support spring nonlinear system under a rectangular pulse," Mathematical Problems in Engineering, vol. 2015, Article ID 910143, 9 pages, 2015.

[19] S. Goyal, E. K. Buratynski, and G. W. Elko, "Role of shock response spectrum in electronic product suspension design," The International Journal of Microcircuits and Electronic Packaging, vol. 23, no. 2, pp. 182-190, 2000.

[20] X. Wu and L. J. Yang, "Natural vibration characteristics of suspension spring geometric nonlinear damping system," Journal of Vibration and Shock, vol. 27, no. 11, pp. 71-72, 2008.

[21] L. Wang and A. Chen, "The damage boundary curve of the suspension packaging system under rectangular pulse," Applied Mechanics and Materials, vol. 105-107, pp. 70-73, 2012.

[22] L. Wang and A. J. Chen, "The Shock response spectra of the suspension packaging system under rectangular pulse," The Journal of Applied Packaging Research, vol. 5, no. 4, pp. 237-246, 2012.

[23] S. Song and A.-J. Chen, "Variational iteration method of dropping shock response for the suspension spring packaging system," Shock and Vibration, vol. 2015, Article ID 408674, 6 pages, 2015.

[24] S. Song, N.-N. Duan, and A.-J. Chen, "Application of variational iteration method for dropping damage evaluation of the suspension spring packaging system," Abstract and Applied Analysis, vol. 2014, Article ID 385404, 7 pages, 2014. 


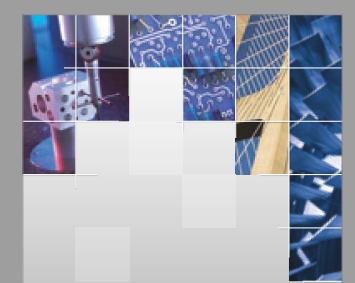

\section{Enfincering}
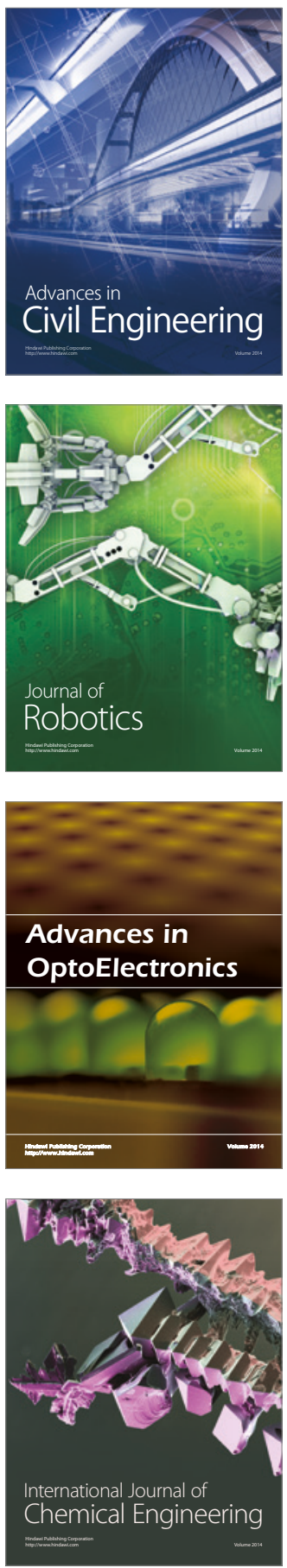

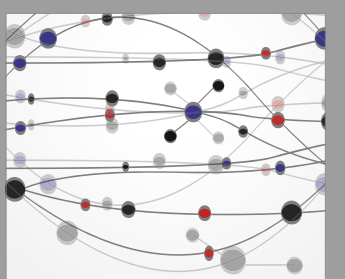

The Scientific World Journal

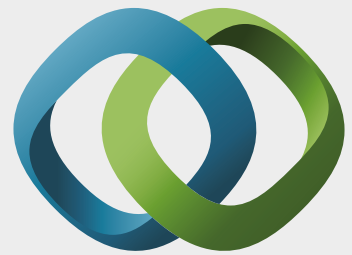

\section{Hindawi}

Submit your manuscripts at

https://www.hindawi.com
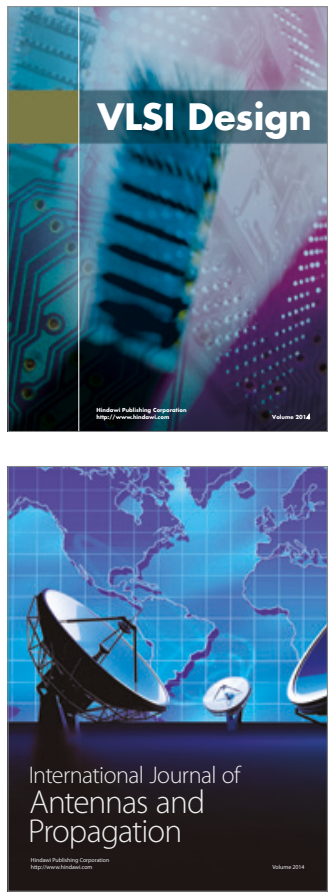

\section{Rotating}

Machinery
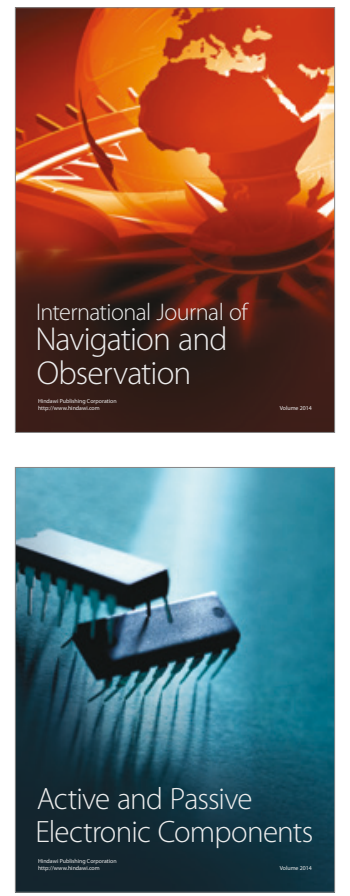
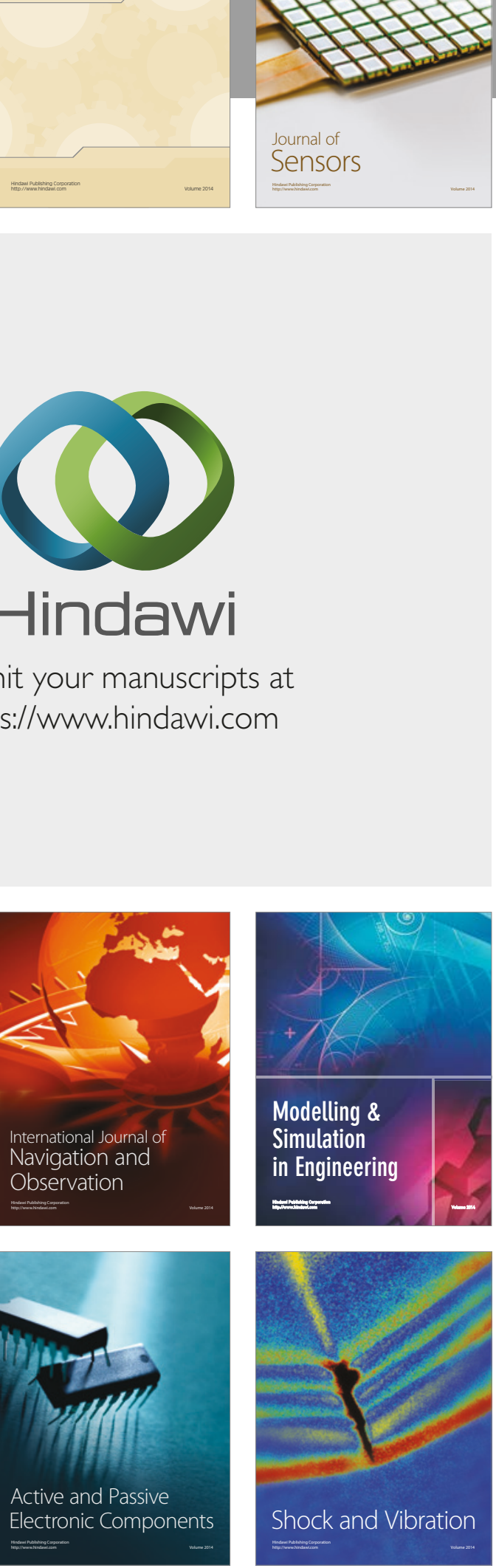
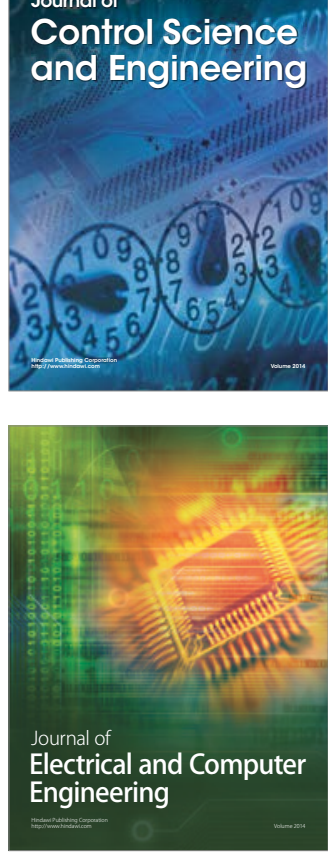

Distributed

Journal of

Control Science

and Engineering
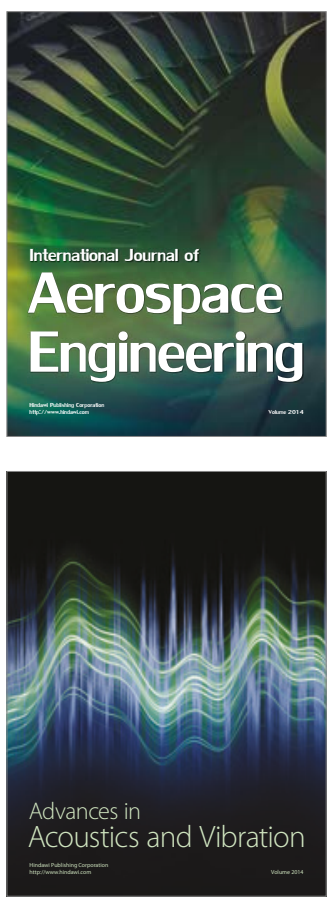

Sensor Networks 